\title{
VĂN HÓA GIAO TIẾP TẠI TRƯờnG ĐẠI HỌC CÔNG NGHIỆP THÀNH PHỐ HỒ CHÍ MINH HIỆN NAY
}

\author{
BIỀN QUỐC THĂNG \\ Trưòng Đại học Công nghiệp Thành phố Hồ Chí Minh; \\ bienthang.iuh@gmail.com
}

Tóm tắt. Bài viết khẳng định văn hóa giao tiếp có ảnh hưởng to lớn đến môi trường sư phạm, cũng như thực hiện mục tiêu giáo dục và đào tạo con người toàn diện. Bên cạnh đi sâu phân tích thực trạng, bài viết đã mạnh dạn đề xuất một số giải pháp nhằm phát triển hơn nữa văn hóa giao tiếp của sinh viên, giảng viên và nhân viên tại Trường Đại học Công nghiệp Thành phố Hồ Chí Minh trong thời gian tới.

Từ khóa. giao tiếp, văn hóa giao tiếp, Trường ĐHCNTPHCM

\section{THE ACTUAL STATE OF COMMUNICATION CULTURE AT THE UNIVERSITY OF INDUSTRY OF HO CHI MINH CITY AT PRESENT}

\begin{abstract}
The article confirms that the communication culture has a great influence on the education environment, as well as the implementation of goals of the comprehensive human education and training. Beside the deep analysis in the actual state, the article forcibly proposed some solution for further development of the communication culture of student, lecturer and employee at the University of Industry of Ho Chi Minh City in the future.
\end{abstract}

Keywords. communication, communication culture, HCMC University of Industry.

\section{MỞ ĐÀ̀}

Trường đại học được xem là một trong những cơ sở, trung tâm văn hóa quan trọng nhất của xã hội. Đây vừa là nơi trang bị tri thức, nâng cao trình độ chuyên môn và cũng là nơi xây dựng, vun đắp các giá trị chuẩn mực, cao quý của xã hội nhằm hướng đến mục tiêu giáo dục, đào tạo con người phát triển toàn diện. Chính vì vậy, từ xưa đến nay, văn hóa luôn gắn liền với hoạt động giáo dục - đào tạo và chính hoạt động giáo dục - đào tạo bao giờ cũng là một trong những nơi biểu hiện cụ thể, sống động, chuẩn mực nhất của văn hóa. Văn hóa ở trường đại học không chỉ thể hiện ở tri thức, sự hiểu biết, chương trình, nội dung đào tạo, văn hóa học, văn hóa dạy, văn hóa tổ chức quản lý, văn hóa ứng xử... mà còn thể hiện thông qua văn hóa giao tiếp - hoạt động không thể thiếu được của mỗi giảng viên, nhân viên, sinh viên.

Trong những năm qua, văn hóa giao tiếp ở trường đại học đã được nghiên cứu ở nhiều góc độ khác nhau, 
đơn cử có các công trình nổi bật như: Phạm Ngọc Trung (2011), "Văn hóa học đường”, Nxb. Chính trị Hành chính, Hà Nội [7]; Đoàn Trọng Thiều (2009), "Giáo dục văn hóa giao tiếp trong nhà truờng: giáo dục cái tâm, cái đẹp", Kỷ yếu hội thảo "Giáo dục văn hóa giao tiếp trong nhà trường” tại Trường Đại học Sư phạm TPHCM [5]; Trần Đình Thích (2011), "Đôi điều suy nghĩ về giáo dục văn hóa giao tiếp trong nhà truờng”, Tạp chí Khoa học Trường ĐH Cần Thơ, số 1 [4]; Mai Thị Thu (2015), "Văn hóa giao tiếp trong thu viện một số truoòng đại học trên địa bàn thành phố Hồ Chí Minh”, Tạp chí Khoa học ĐHSP TPHCM, số 10 [6]; Nguyễn Thị Từ Huy (2013), "Xung hô trong truờng học ngày nay", http://vietnamnet.vn, truy cập ngày 26/03/2018 [3]... Có thể nói, các nghiên cứu tiêu biểu kể trên một mặt đã cung cấp cho người đọc thấy được sự đa dạng, phong phú của hoạt động giao tiếp; mặt khác, nêu bật được các hình thức biểu hiện, cũng như lột tả được các đặc trưng cơ bản, các chuẩn mực cần thiết của hoạt động này trong nhà trường. Giá trị của các nghiên cứu trên sẽ là tiền đề quan trọng để chúng tôi kế thừa, hoàn thiện nội dung nghiên cứu văn hóa giao tiếp tại Trường Đại học Công nghiệp Thành phố Hồ Chí Minh (ĐHCNTPHCM).

Tại Trường ĐHCNTPHCM, hoạt động giao tiếp của sinh viên, giảng viên và nhân viên thời gian qua đã có những chuyển biến khá tích cực, góp phần không nhỏ vào sự nghiệp xây dựng và phát triển toàn diện của nhà trường. Tuy nhiên, phải thẳng thắn thừa nhận rằng: hoạt động giao tiếp của sinh viên, giảng viên và nhân viên ở nơi đây vẫn còn bộc lộ một số hạn chế. Sự hạn chế đó không chỉ ảnh hưởng đến môi trường sư phạm, chất lượng đào tạo, mà còn ảnh hưởng đến uy tín, thương hiệu của Trường trong đời sống xã hội. Thế nhưng, vấn đề này đến nay vẫn chưa có công trình nào nghiên cứu trình bày một cách đầy đủ, bài bản. Chính vì vậy, trước yêu cầu: "Xây dựng mỗi trường học phải thực sự là một trung tâm văn hóa giáo dục, rèn luyện con người về lý tưởng, phẩm chất, nhân cách, lối sống” [1, tr.51]; và trước sứ mệnh phát triển Trường ĐHCNTPHCM "trở thành trường đại học trọng điểm quốc gia có vai trò tiên phong đối với sự phát triển của các trường thuộc Bộ Công Thương”[9]; thì việc đi sâu phân tích một cách khách quan, có hệ thống nhằm làm sáng tỏ thực trạng văn hóa giao tiếp của đội ngũ giảng viên, nhân viên và lực lượng sinh viên; trên cơ sở đó đề ra các giải pháp nhằm hoàn thiện, phát triển văn hóa giao tiếp ở nơi đây tốt hơn ở thời gian tới là một trong những vấn đề có tính cấp thiết đối với Trường ĐHCNTPHCM.

\section{THỰC TRẠNG VĂN HÓA GIAO TIÊP CỦA SINH VIÊN, GIẢNG VIÊN VÀ NHÂN VIÊN TẠI TRƯỜNG ĐHCNTPHCM HIÊN NAY}

Trong đời sống, con người không chỉ có mối quan hệ với thế giới tự nhiên mà còn có mối quan hệ giữa người với người trong xã hội - quan hệ đó được gọi là giao tiếp. Theo cách hiểu thông thường, giao tiếp là quá trình tác động qua lại và thể hiện sự tiếp xúc tâm lí giữa người với người, thông qua đó con người thực hiện việc trao đổi thông tin, chia sẻ cảm xúc, chi phối và chịu sự ảnh hưởng lẫn nhau. Hay nói cách khác, "giao tiếp là quá trình xác lập và vận hành các quan hệ nguời - người, hiện thưc hóa các quan hệ xã họi giữa chủ thể này với chủ thể khác” [8, tr.49]. Ở trường đại học, chủ thể đông đảo và cơ bản nhất xác lập, 
vận hành quá trình giao tiếp đó chính là đội ngũ giảng viên, nhân viên, lực lượng sinh viên liên quan đến các hoạt động giảng dạy, học tập, cũng như các hoạt động khác trong phạm vi trường học. Với đặc thù là nơi diễn ra các hoạt động giáo dục và đào tạo, nên nội dung, cách thức, hành vi... giao tiếp ở trường đại học tất yếu phải có văn hóa - nghĩa là dựa trên các mục tiêu của giáo dục và hướng đến sự chuẩn mực cao nhất của xã hội. Là một bộ phận của phạm trù văn hóa, văn hóa giao tiếp là tổng hợp các thành tố cơ bản của lời nói, cử chỉ, hành vi, thái độ, cách ứng xủ...giữa người với nguời thể hiện một cách lịch sự, thân thiện, cởi mở, chân thành, tôn trọng lẫn nhau. Để thực hiện nghiên cứu này, bên cạnh các phương pháp như: phân tích và tổng hợp, so sáng và đối chiếu, lôgích và lịch sử, quan sát...chúng tôi đã tiến hành điều tra xã hội học vào tháng 01/2018 tại Trường với các nội dung và kết quả như sau:

I. Thông tin định danh

Đơn vị tính: \%

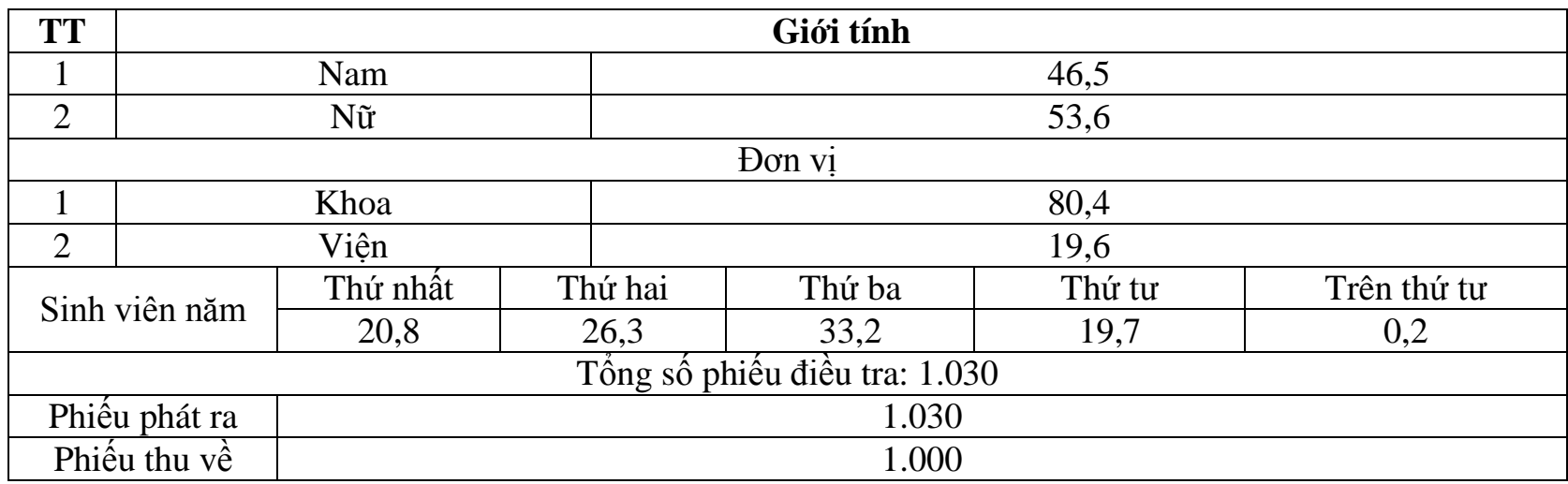

\section{Kết quả điều tra}

Bảng 1: Đánh giá của sinh viên về thái độ của giảng viên và nhân viên khi giao tiếp với sinh viên tại Trường ĐHCNTPHCM

\begin{tabular}{|c|l|c|c|}
\hline \multicolumn{1}{|c|}{ MTức độ } & Giảng viên & Nhân viên \\
\hline 1 & Rất cởi mở, vui vẻ và thân thiện & 24,9 & 7,8 \\
\hline 2 & Cởi mở, vui vẻ và thân thiện & 48,3 & 27,3 \\
\hline 3 & Tương đối cởi mở, vui vẻ và thân thiện & 24,7 & 53,7 \\
\hline 4 & Không cởi mở, vui vẻ và thân thiện & 2,2 & 11,3 \\
\hline
\end{tabular}

Bảng 2: Đánh giá của sinh viên về cách thức giao tiếp của giảng viên và nhân viên với sinh viên tại Trường ĐHCNTPHCM

\begin{tabular}{|c|c|c|c|c|c|c|c|c|c|c|}
\hline \multirow{2}{*}{ TT } & \multirow{2}{*}{$\begin{array}{c}\text { Rất không } \\
\text { tốt }\end{array}$} & \multicolumn{2}{|c|}{ Không tốt } & \multicolumn{2}{c|}{ Bình thường } & \multicolumn{3}{|c|}{ Tốt } & \multicolumn{2}{c|}{ Rất tốt } \\
\cline { 3 - 12 } & $\mathrm{GV}$ & $\mathrm{NV}$ & $\mathrm{GV}$ & $\mathrm{NV}$ & $\mathrm{GV}$ & $\mathrm{NV}$ & $\mathrm{GV}$ & $\mathrm{NV}$ & $\mathrm{GV}$ & $\mathrm{NV}$ \\
\hline
\end{tabular}




\begin{tabular}{|c|l|c|c|c|c|c|c|c|c|c|c|}
\hline 1 & $\begin{array}{l}\text { Mức độ phổ thông } \\
\text { của việc sử dụng } \\
\text { từ ngữ }\end{array}$ & 1,1 & 3,9 & 3,9 & 6,7 & 19,0 & 33,1 & 45 & 42,0 & 30,7 & 14,3 \\
\hline 2 & $\begin{array}{l}\text { Mức độ rõ ràng, } \\
\text { mạch lạc, dễ hiểu }\end{array}$ & 0,9 & 1,7 & 4,3 & 10,0 & 22,3 & 36,4 & 51,1 & 40,5 & 21,4 & 11,5 \\
\hline 3 & $\begin{array}{l}\text { Mức độ truyền } \\
\text { cảm, có điểm nhấn } \\
\text { ở nội dung chính }\end{array}$ & 1,5 & 3,9 & 4,3 & 11,5 & 28,2 & 38,1 & 41,3 & 37,4 & 24,7 & 9,1 \\
\hline 4 & $\begin{array}{l}\text { Mức độ phù hợp } \\
\text { giữa lời nói với cử } \\
\text { chỉ, điệu bộ }\end{array}$ & 0,9 & 3,7 & 3,9 & 11,5 & 23,2 & 36,1 & 48,3 & 37,4 & 23,7 & 11,3 \\
\hline
\end{tabular}

Bảng 3: Đánh giá của sinh viên về mức độ sử dụng các phương tiện hiện đại như: điện thoại, email, facebook, zalo, viber của giảng viên và nhân viên để giao tiếp với sinh viên tại Trường ĐHCNTPHCM

\begin{tabular}{|c|c|c|c|c|c|}
\hline TT & Đối tượng & Không bao giờ & Thỉnh thoảng & Thường xuyên & $\begin{array}{c}\text { Rất thường } \\
\text { xuyên }\end{array}$ \\
\hline 1 & Giảng viên & 6,1 & 39,4 & 46,5 & 8,0 \\
\hline 2 & Nhân viên & 28,4 & 43,5 & 25,7 & 2,4 \\
\hline
\end{tabular}

Bảng 4: Sinh viên Trường ĐHCNTPHCM tự đánh giá về các hành vi của mình:

\begin{tabular}{|c|l|c|c|c|c|}
\hline TT & \multicolumn{1}{|c|}{ Nội dung } & $\begin{array}{c}\text { Không } \\
\text { bao giờ }\end{array}$ & Ít khi & $\begin{array}{c}\text { Thỉnh } \\
\text { thoảng }\end{array}$ & $\begin{array}{c}\text { Thường } \\
\text { xuyên }\end{array}$ \\
\hline 1 & Nói tục, chửi thề trong phạm vi Trường & 65.6 & 21.6 & 9.1 & 3.7 \\
\hline 2 & Nghe điện thoại trong lớp học & 29.7 & 45.9 & 18.6 & 5.8 \\
\hline 3 & Nói chuyện trong giờ học & 11.0 & 34.4 & 44.8 & 9.7 \\
\hline 4 & Chào hỏi thầy/cô/khách... tới Trường & 2.6 & 13.4 & 48.3 & 35.7 \\
\hline
\end{tabular}

\subsection{Giao tiếp giữa sinh viên với sinh viên}

Do có sự tương đồng về độ tuổi, tính cách, nên hoạt động giao tiếp giữa sinh viên với sinh viên tại Trường ĐHCNTPHCM diễn ra khá sôi nổi, đa dạng và phong phú. Trong lớp học hay trong các hoạt động đoàn thể, đại đa số sinh viên thường sử dụng các đại từ xưng hộ khá lịch sự như: bạn - mình, bạn tôi... Hành vi giao tiếp giữa sinh viên với nhau nhìn chung khá thân thiện và cởi mở. Mặc dù đến từ nhiều vùng, miền với nhiều giọng nói, âm lượng, ngữ điệu khác nhau; song, trong giao tiếp, đại đa số sinh viên 
Trường ĐHCNTPHCM tỏ ra rất hòa đồng và hòa nhập nhanh. Đặc biệt, một số sinh viên năm thứ nhất, chỉ sau vài tháng nhập học đã điều chỉnh được âm lượng, giọng nói, ngữ điệu của mình để phù hợp với môi trường sinh sống, học tập ở vùng đất phương Nam. Hoạt động giao tiếp của sinh viên nói chung, sinh viên Trường ĐHCNTPHCM nói riêng ngày nay không chỉ trực tiếp - mặt đối mặt, mà còn thông qua gián tiếp nhờ các phương tiện hiện đại hỗ trợ như: điện thoại, email, facebook, viber, zalo... Mục đích giao tiếp của sinh viên cũng không chỉ dừng lại ở việc trao đổi, chia sẽ thông tin về chuyện học hành, thi cử, về các hoạt động của đoàn thể mà còn nhiều vấn đề khác trong cuộc sống.

Tuy nhiên, hoạt động giao tiếp giữa sinh viên với sinh viên tại Trường ĐHCNTPHCM hiện đang bộc lộ một số hạn chế. Đơn cử như, một số sinh viên, nhất là sinh viên nam vẫn còn dùng những từ ngữ thô tục trong giao tiếp. Kết quả điều tra cho thấy, có $9,1 \%$ sinh viên tự thừa nhận mình thỉnh thoảng, 3,7\% sinh viên tự thừa nhận mình thường xuyên nói tục, chửi thề trong phạm vi trường học [Bảng 4]. Một số sinh viên khi giao tiếp với nhau còn nói với tốc độ quá nhanh, hoặc quá lạm dụng từ ngữ địa phương (chủ yếu sinh viên ở vùng Bắc Trung Bộ) đã làm cho một số sinh viên ở các vùng, miền khác (nhất là ở vùng miền Tây Nam Bộ) khó nghe, khó tiếp nhận, khó hiểu nội dung truyền tải. Một số sinh viên cả nam và nữ vẫn còn cẩu thả trong việc lựa chọn từ ngữ kém văn hóa để thực hiện giao tiếp. Việc giao tiếp không đúng nơi, đúng chỗ, đúng thời điểm cũng diễn ra khá phổ biến đối với sinh viên. Theo kiết quả điều tra, tỷ lệ sinh viên nói chuyện riêng trong lớp học vẫn còn khá cao: có $44,8 \%$ sinh viên tự thừa nhận mình thỉnh thoảng và 9,7\% sinh viên tự thừa nhận mình thường xuyên nói chuyện trong giờ học [Bảng 4]. Việc sử dụng điện thoại di động ngày nay đã trở nên phổ biến, "vật bất ly thân" đối với mọi người nhất là đối với thế hệ trẻ. Tuy nhiên, sử dụng điện thoại như thế nào để giao tiếp một cách có văn hóa ở trường đại học không phải sinh viên nào cũng ý thức và thực hiện được; kết quả điều tra cho thấy: có $18,6 \%$ sinh viên tự thừa nhận mình thỉnh thoảng và 5,8\% sinh viên tự thừa nhận mình thường xuyên sử dụng điện thoại trong lớp học [Bảng 4]. Kết quả trên phần nào phản ánh, ý thức, sự tập trung trong học tập của một bộ phận sinh viên tại Trường ĐHCNTPHCM chưa cao. Do đó, thời gian tới rất cần các giải pháp kịp thời để thiết lập kỷ cương, nề nếp học tập của sinh viên nhằm đảm bảo chất lượng đào tạo.

Đặc biệt những năm gần đây, qua quan sát chúng tôi nhận thấy: trong quá trình giao tiếp với nhau, một số sinh viên tại Trường ĐHCNTPHCM thường hay sử dụng các từ lóng, tiếng lóng, hoặc cố tình thay đổi cách viết các cấu trúc câu, cố tình viết lệch âm, sai lỗi chính tả như: tiền thành "xiền", yêu thành "iu", cơm thành "kom", "buồn như chuồn chuồn", "ghét như bọ chét", "tào lao bí đao", "nhỏ như con thỏ", "bốc hơi” (biến mất), “đít chai” (kính cận thị)... Có thể nói, việc sử dụng các từ ngữ "tuổi teen”, ngôn ngữ “chát” phần nào đó đã tạo được sự cộng cảm trong một bộ phận giới trẻ. Một số ý kiến cho rằng, đó là biểu hiện của sự hồn nhiên, vui tươi, tự do, gần gủi nhằm thu hẹp khoảng cách, tạo sự tiện lợi giữa bạn bè với nhau. Tuy nhiên, theo chúng tôi, giao tiếp là hoạt động một mặt thực hiện nhiệm vụ truyền đạt thông tin, mặt khác còn là phương diện thể hiện văn hóa, đạo đức, nhân cách, thái độ của người thực hiện hành vi giao tiếp. Vì vậy, việc quá lạm dụng các thuật ngữ "lệch chuẩn" không chỉ ảnh hưởng đến việc 
giữ gìn sự trong sáng của tiếng Việt, mà còn ảnh hưởng đến việc xây dựng lối sống, nhân cách của sinh viên, những người được xem là chủ nhân tương lai của đất nước. Do đó, trong thời gian tới các cá nhân, đơn vị có trách nhiệm ở Trường cần đề ra các giải pháp nhằm định hướng, uốn nắn, giáo dục sinh viên, để họ nhận thức được các chuẩn mực cần thiết trong giao tiếp; từ đó làm cơ sở cho việc xây dựng một môi trường sư phạm văn minh, lịch sự, nhằm nâng cao chất lượng nguồn nhân lực.

\subsection{Giao tiếp giữa giảng viên, nhân viên với sinh viên}

Ở trường đại học, giao tiếp giữa giảng viên và nhân viên với sinh viên chủ yếu diễn ra liên quan đến hoạt động giảng dạy, học tập, thực thi các nội quy, quy chế của nhà trường... Trong khi giải quyết các mối liên hệ, thực thi các nhiệm vụ đó thì thái độ của các chủ thể trong giao tiếp không chỉ là ấn tượng ban đầu mà còn là tín hiệu báo trước cho một cuộc giao tiếp thành công hay thất bại. Bởi vì, trong hoạt động giao tiếp, nếu một bên có thái độ cởi mở, vui vẻ, nhiệt tình thì bên còn lại sẽ có tâm lý thoải mái, sự tự tin, có thời gian và điều kiện để trình bày đầy đủ nội dung, mục đích của việc giao tiếp. Còn ngược lại, sẽ rất khó để đạt được mục đích khi thực hiện việc giao tiếp. Đối với sinh viên, trong quá trình giao tiếp với giảng viên và nhân viên, nếu hai chủ thể trên có thái độ thiếu cởi mở, vui vẻ, thân thiện thì không chỉ tạo cho sinh viên ấn tượng xấu, mà còn làm cho sinh viên - đối tượng được xem là yếu thế hơn mất bình tĩnh, cảm thấy thiếu tự tin, ít có thời gian và điều kiện để trình bày một cách đầy đủ, rõ ràng về nội dung cần trao đổi - hệ quả là cuộc giao tiếp khó mang lại kết quả tốt. Từ kết quả điều tra cho thấy: đại đa số sinh viên đánh giá thái độ của giảng viên khi giao tiếp với sinh viên tại Trường khá tích cực: có 24,9\% ý kiến sinh viên đánh giá giảng viên rất cởi mở, vui vẻ và thân thiện; có 48,3\% ý kiến sinh viên đánh giá giảng viên cởi mở, vui vẻ và thân thiện. Số lượng giảng viên không cởi mở, vui vẻ và thân thiện khi giao tiếp với sinh viên chiếm tỷ lệ không đáng kể 2,2\% [Bảng 1].

Nếu như thái độ giao tiếp của giảng viên với sinh viên khá tích cực, thì thái độ giao tiếp của nhân viên với sinh viên tại Trường lại làm cho các cá nhân, đơn vị có trách nhiệm phải lưu ý. Theo kết quả điều tra, chỉ có 7,8\% ý kiến sinh viên đánh giá, nhân viên rất cởi mở, vui vẻ và thân thiện khi giao tiếp với sinh viên; có $27,2 \%$ ý kiến sinh viên đánh giá là cởi mở, vui vẻ và thân thiện; còn tỷ lệ tương đối cởi mở, vui vẻ và thân thiện và không cởi mở, vui vẻ và thân thiện của nhân viên trong quá trình giao tiếp với sinh viên chiếm tỷ lệ khá cao 65\% [Bảng 1]. Có thể nói, trong những năm qua, Đảng ủy, Ban Giám hiệu luôn quán triệt quan điểm: sinh viên là khách hàng, đối tượng phục vụ chính của nhà trường. Thực trạng trên không chỉ phản ánh một số giảng viên, nhân viên chưa thực hiện đúng quan điểm, chủ trương của nhà trường; mặc khác còn cho thấy sự cởi mở, văn minh và thân thiện tại Trường chưa cao. Chính vì vậy, một số đơn vị, cá nhân liên quan cần nhìn nhận vấn đề này một cách khách quan, cầu thị, để từ đó có các biện pháp phục kịp thời thực trạng trên.

Bên cạnh thái độ - bước đầu tiên của quá trình giao tiếp, thì bước tiếp theo là cách thức giao tiếp - cách truyền đạt thông tin giữa các chủ thể cũng ảnh hưởng không nhỏ đến sự thành công của một cuộc giao tiếp. Bởi, nếu chủ thể giao tiếp sử dụng các từ ngữ phổ thông, diễn đạt một cách rõ ràng, mạch lạc với 
chất giọng truyền cảm, có điểm nhấn cộng với sự phù hợp giữa lời nói và cử chỉ, điệu bộ thì mục đích của việc truyền đạt thông tin mang lại kết quả tích cực - nhất là trong hoạt động giảng dạy của giảng viên - hoạt động vừa cần sự chính xác, khoa học của nội dung, vừa cần hội đủ các nhân tố mang tính hình thức kể trên để tạo nên giờ giảng hay, tiết học hấp dẫn - cơ sở quan trọng để nâng cao chất lượng giáo dục và đào tạo tại Trường. Từ kết quả điều tra cho thấy, cách thức giao tiếp của đa số giảng viên, nhân viên tại Trường được sinh viên đánh giá từ bình thường đến tốt và rất tốt chiếm tỷ lệ từ $85 \%$ trở lên [Bảng 2]. Kết quả đó, một mặt phản ánh chất lượng hoạt động giảng dạy của đội ngũ giảng viên khá cao, mặt khác cho chúng ta biết được chất lượng giải quyết các công việc của đội ngũ nhân viên phục vụ đào tạo tại Trường cũng được sinh viên đánh giá khá tích cực.

Ngày nay, trước sự phát triển mạnh mẻ của cuộc cách mạng khoa học và công nghệ, đặc biệt là công nghệ thông tin đã làm cho cách thức giao tiếp của con người với nhau phong phú, đa dạng, nhiều hơn so với trước. Việc sử dụng các phương tiện hiện đại như: điện thoại, email, facebook, zalo, viber trong giao tiếp giờ đây đã trở nên phổ biến đối với mọi người, nhất là giảng viên, nhân viên, sinh viên. Kết quả điều tra cho thấy: đại đa số giảng viên, nhân viên tại Trường ĐHCNTPHCM đã sử dụng các phương tiện hiện đại để giao tiếp với sinh viên, song mức độ còn rất khác nhau. Tỷ lệ giảng viên sử dụng các phương tiện hiện đại để giao tiếp với sinh viên chiếm tỷ lệ cao hơn so với nhân viên. Sự chênh lệch này cũng dễ dàng lý giải, bởi do đặc thù của công việc nên giảng viên cần có sự liên hệ với sinh viên nhiều hơn nhằm trao đổi thông tin về các vấn đề liên quan đến học tập. Tuy nhiên, vẫn còn một bộ phận giảng viên (6\%), nhân viên (28\%) không bao giờ sử dụng các phương tiện hiện đại để trao đổi thông tin với sinh viên [Bảng 3]. Sự hạn chế đó không chỉ thể hiện sự đơn điệu trong hoạt động giao tiếp của giảng viên và nhân viên; mà còn cho thấy sự nhiệt tình, mức độ quan tâm của giảng viên, nhân viên trong việc truyền đạt, cung cấp thông tin kịp thời, đầy đủ cho sinh viên còn rất hạn chế.

\subsection{Giao tiếp giữa sinh viên với giảng viên và nhân viên}

Nhìn chung, đại đa số sinh viên tại Trường ĐHCNTPHCM giao tiếp với giảng viên, nhân viên khá văn minh, lịch sự. Hoạt động giao tiếp của đại đa số sinh viên tại Trường một mặt đã thể hiện sự "tôn sư trọng đạo" ở môi trường sư phạm, mặt khác cũng đã thể hiện được sự dân chủ, bình đẳng trong việc trao đổi thông tin. Nhiều sinh viên không chỉ lễ phép mà còn biết chọn lọc những từ ngữ phù hợp, diễn đạt một cách lôgích, dễ nghe, dễ hiểu trong quá trình giao tiếp với giảng viên và nhân viên. Trên thực tế, một số sinh viên đã khá mạnh dạn, cởi mở khi tâm sự với giảng viên, nhân viên về những vấn đề trong học tập lẫn trong cuộc sống. Chính sự cởi mở, cầu thị, sự chân thành chia sẻ của sinh viên đã giúp cho một số giảng viên, nhân viên nắm bắt được nhu cầu, thị hiếu, hiểu được hoàn cảnh, tâm trạng để từ đó có sự động viên, tư vấn, định hướng giúp sinh viên một cách kịp thời, có hiệu quả. Không những thế, thông qua quá trình giao tiếp, trao đổi thông tin đã làm cho mối liên hệ giữa giảng viên, nhân viên với sinh viên, cũng như khoảng cách giữa gia đình với nhà trường được thu hẹp, ngày thêm gắn bó mật thiết.

Tuy nhiên, trong quá trình giao tiếp với giảng viên và nhân viên, một bộ phận sinh viên tại Trường 
ĐHCNTPHCM vẫn còn tỏ ra ngại ngùng, rụt rè, run sợ, không dám phát biểu, hay nêu lên ý kiến của riêng mình. Một số sinh viên khi tiếp xúc trực tiếp với giảng viên, nhân viên rất lịch sự, văn minh; song, khi không có mặt hoặc khi không còn giảng dạy nữa thì dùng những đại từ nhân xưng để gọi giảng viên, nhân viên rất khiếm nhã như: "ông ấy”, "bà ấy”, "cha ấy”, "lão ấy”... Một số sinh viên vẫn còn giữ thói quen xưng "con”, và ngược lại, một số giảng viên, nhân viên cũng gọi sinh viên bằng "con" trong giao tiếp tại Trường. Chúng tôi cho rằng, việc xưng hô như vậy đã vô tình đồng nhất quan hệ ở trường học với quan hệ ở gia đình. Vì vậy, cần phải có cách thức xưng hô vừa thể hiện được tính tôn ti, thứ bậc, vừa thể hiện sự bình đẳng, dân chủ, ý thức được cái tôi, cá nhân tương xứng với sự trưởng thành của sinh viên. Bên cạnh đó, một số sinh viên vẫn chưa thể hiện được hành vi giao tiếp có văn hóa của mình, nhất là trong việc chào hỏi. Kết quả điều tra cho thấy, có $2,6 \%$ sinh viên không bao giờ chào hỏi, $13,4 \%$ sinh viên ít khi, 48,3\% sinh viên thỉnh thoảng và chỉ có $35,7 \%$ sinh viên thường xuyên chào hỏi giảng viên, nhân viên hay khách đến thăm, làm việc tại Trường [Bảng 4].

Như vậy, bên cạnh những kết quả đạt được, hoạt động giao tiếp của một bộ phận giảng viên, nhân viên và sinh viên tại Trường ĐHCNTPHCM vẫn còn tồn tại một số hạn chế. Những tồn tại, hạn chế đó không chỉ đã và đang làm ảnh hưởng đến chất lượng hoạt động giảng dạy và học tập tại Trường; mà còn góp phần làm giảm sút uy tín, hình ảnh, thương hiệu của Trường trong đời sống xã hội. Chính vì vậy, đề ra các giải pháp khoa học để khắc phục những tồn tại, hạn chế kể trên nhằm xây dựng môi trường sư phạm văn minh, lịch sự, có văn hóa cao là một yêu cầu có tính cấp thiết.

\section{MỘT SỐ GIẢI PHÁP CƠ BẢN NHẰM PHÁT TRIỂN VĂN HÓA GIAO TIẾP TẠI TRUOÒNG ĐHCNTPHCM TRONG THỜI GIAN TỚI}

Có thể khẳng định: một môi trường sư phạm giao tiếp có văn hóa không chỉ là cơ sở để giáo dục, bồi dưỡng và phát triển nhân cách cao đẹp cho sinh viên; mà còn là tiền đề quan trọng giúp sinh viên xây dựng, hình thành các thói quen, điều kiện cần thiết để sinh viên rèn luyện thành thạo các kỹ năng giao tiếp, làm cơ sở cho việc tạo lập các mối quan hệ tốt đẹp sau khi ra trường "lập thân, lập nghiệp". Do đó, thời gian tới, các đơn vị, tổ chức, cá nhân tại Trường ĐHCNTPHCM cần phát huy những giá trị tích cực đã đạt được, bên cạnh đó cần thực hiện một số giải pháp nhằm khắc phục những tồn tại, hạn chế kể trên để xây dựng, phát triển hơn nữa văn hóa giao tiếp ở nơi đây. Trong phạm vi bài viết này, chúng tôi kiến nghị một số giải pháp cơ bản như:

\subsection{Cần nâng cao nhận thức về tầm quan trọng của văn hóa giao tiếp cho đội ngũ giảng viên, nhân viên và lực lượng sinh viên}

Giao tiếp là hoạt động không thể thiếu được đối với mỗi người, tuy nhiên không phải ai cũng nhận thức được tầm quan trọng của nó. Hệ quả là một số giảng viên, nhân viên và sinh viên tại Trường ĐHCNTPHCM vẫn còn có thái độ, hành vi, cách thức giao tiếp chưa đúng mực ở môi trường sư phạm. Chính vì vậy, Đảng ủy, Ban Giám hiệu và các bộ phận có liên quan cần đẩy mạnh công tác tuyên truyền để mỗi giảng viên, đặc biệt là mỗi nhân viên và sinh viên hiểu đúng, đầy đủ về tầm quan trọng 
của việc giao tiếp có văn hóa tại trường đại học. Bên cạnh đó, cần tăng cường công tác giáo dục bằng cách mở các lớp giáo dục kỹ năng mềm, nhất là kỹ năng giao tiếp, ứng xử cho một số giảng viên, nhất là đội ngũ nhân viên phục vụ đào tạo ở các Khoa, Viện, Phòng, Ban và lực lượng sinh viên; nhằm trang bị cho họ những tri thức, kỹ năng cần thiết để từ đó giúp họ tự tin, lịch sự, văn minh hơn khi thực hiện hoạt động giao tiếp tại Trường ĐHCNTPHCM.

\subsection{Cần ban hành bộ quy tắc giao tiếp tại Trường}

Trước thực trạng cách thức, hành vi, từ ngữ... trong giao tiếp của đội ngũ giảng viên, nhân viên và lực lượng sinh viên chưa có sự thống nhất, phù hợp và phần nào đó thể hiện sự mất phương hướng do chưa có một quy chuẩn trên thực tế. Chính vì vậy, trong thời gian tới, các bộ phận có liên quan tại Trường ĐHCNTPHCM cần xây dựng và ban hành bộ quy tắc giao tiếp học đường dành cho giảng viên, nhân viên và sinh viên; để từ đó các chủ thể trên biết những hành vi, thái độ, cách xưng hô như thế nào là phù hợp, đúng quy định và có văn hóa. Khi xây dựng bộ quy tắc giao tiếp học đường, Trường cần kế thừa những giá trị truyền thống giao tiếp tốt đẹp của dân tộc; mặc khác cũng phải biết tiếp thu có chọn lọc những tinh hoa văn hóa giao tiếp tiên tiến của nhân loại phù hợp với đặc điểm, tâm lý, tình cảm, nghề nghiệp...đặc thù của con người Việt Nam và đối tượng là giảng viên, nhân viên, sinh viên ở trường đại học. Bên cạnh đó, Trường cũng cần mạnh dạn dứt khoát với những tư tưởng bảo thủ, cứng nhắc, ảnh hưởng từ nền giáo dục hủ nho lạc hậu trước đây để xây dựng bộ quy tắc giao tiếp vừa bình đẳng và dân chủ, vừa lịch sự và văn minh.

\subsection{Cần tăng cường sự giám sát và có chính sách khen thưởng, xử phạt nghiêm minh, kịp thời đối với cá nhân có hành vi giao tiếp kém văn hóa}

Hoạt động giao tiếp phụ thuộc rất lớn vào tâm lý, tình cảm, bối cảnh của chủ thể giao tiếp. Thế nên, trên thực tế không phải ai, không phải khi nào cũng có cách thức, hành vi giao tiếp được mọi người yêu quý, kính trọng. Chính vì vậy, nhà Trường cần giao cho một tổ chức và trang bị thêm các phương tiện hiện đại để theo dỏi, giám sát hoạt động giao tiếp của đội ngũ giảng viên, nhân viên, lực lượng sinh viên. Từ thực trạng một bộ phận không nhỏ nhân viên vẫn còn có thái độ, hành vi giao tiếp chưa đúng mực với sinh viên; nên chăng Trường cần thiết lập một đường dây nóng, lắp đặt thêm một số camera ở những nơi sinh viên và nhân viên thường tiếp xúc, trao đổi với nhau như: văn phòng tiếp sinh viên ở các Khoa, Viện, Phòng, Ban. Khi phát hiện hoặc khi nhận được phản ánh từ sinh viên, giảng viên, nhân viên qua các kênh thông tin khác nhau; Trường cần kịp thời xác minh và có các biện pháp giải quyết. Nếu cá nhân, tổ chức, đơn vị nào thực hiện tốt nội quy, quy chế giao tiếp học đường, Trường nên có chính sách tuyên dương, khen thưởng một cách thích đáng; ngược lại, nếu vi phạm Trường cần phải xử lý nghiêm minh theo các quy định của Trường và nhà pháp luật; hoặc thay thế, bố trí nhân sự khác làm việc.

\subsection{Cần phát huy tính tích cực, tinh thần tự giác, tự tu dưỡng, tự rèn luyện của bản thân mỗi giảng viên, nhân viên và sinh viên}

Nếu như các yếu tố trên được xây dựng, triển khai một cách đầy đủ, có hệ thống mà tính tích cực, sự tự 
giác, tự ý thức, tự tu dưỡng, rèn luyện của mỗi giảng viên, nhân viên và sinh viên hạn chế thì hoạt động giao tiếp ở Trường ĐHCNTPHCM cũng khó có sự chuyển biến, mang lại kết quả tích cực. Chính vì vậy, bản thân mỗi giảng viên, nhân viên và sinh viên phải luôn tự tu dưỡng, tự rèn luyện không ngừng, không được thỏa mãn, bằng lòng với bản thân. Mỗi giảng viên, nhân viên và sinh viên luôn tự ý thức để biết rằng: mối quan hệ giữa giảng viên, nhân viên với sinh viên là mối quan hệ tương hỗ, cùng nhau phát triển. Bởi nếu không có sinh viên tất yếu sẽ không có sự tồn tại của nhà trường - đồng nghĩa với không có việc làm, không có thu nhập, đặc biệt trong bối cảnh Trường đang thực hiện quy chế tự chủ, tự chịu trách nhiệm như hiện nay. Ngược lại, mỗi sinh viên cũng luôn khắc cốt, ghi tâm rằng: chính giảng viên và nhân viên là những người có công lao to lớn trong việc giáo dục và đào tạo mình nên người. Do đó, mỗi thái độ, hành vi, lời nói của mỗi giảng viên, nhân viên, sinh viên phải thể hiện phù hợp với lời ông cha ta từng răn dạy: "Lời nói chẳng mất tiền mua, lựa lời mà nói cho vừa lòng nhau". Đặc biệt, đối với mỗi giảng viên phải luôn tự tu dưỡng, rèn luyện bản thân mình để không chỉ là tấm gương sáng về tri thức, trí tuệ, chí tự học, tự đào tạo; mà còn là tấm gương sáng về đạo đức, nhân cách cho bao thế hệ sinh viên ở Trường noi theo.

\section{KẾT LUẬN}

Từ lâu, Đảng ta đã khẳng định: "Văn hóa là nền tảng tinh thần của xã hội, vừa là mục tiêu vừa là động lực thúc đẩy sự phát triển kinh tế - xã hội” [2, tr.89]. Sinh thời, cố Thủ tướng Phạm Văn Đồng đã từng nói: muốn có xã hội tốt phải có con người tốt. Muốn có con người tốt phải có môi trường tốt. Đây là quan hệ biện chứng, thiên biến vạn hóa giữa xã hội và con người. Thế nên, xây dựng văn hóa giao tiếp ở Trường ĐHCNTPHCM không chỉ tạo lập một môi trường sư phạm lành mạnh, điều kiện cần thiết để mỗi sinh viên, giảng viên và nhân viên rèn luyện, phấn đấu và trưởng thành; mà còn là nhân tố "nội sinh" quan trọng tạo nên động lực thúc đẩy sự phát triển của Trường cũng như của xã hội. Phát triển văn hóa giao tiếp ở thang bậc cao là một công việc lâu dài, khó khăn và vô cùng phức tạp. Chính vì vậy, thời gian tới đòi hỏi mỗi cá nhân, đơn vị, đặc biệt là bản thân mỗi giảng viên, nhân viên và sinh viên phải luôn cố gắng, kiên trì, quyết tâm cao trong việc xây dựng văn hóa giao tiếp ở Trường ĐHCNTPHCM phát triển một cách toàn diện và bền vững.

\section{TÀI LIÊUU THAM KHẢO}

[1] Đảng Cộng sản Việt Nam (2014), Văn kiện Hội nghị lần thứ chín Ban chấp hành Trung ương khóa XI, Văn phòng Trung ương Đảng.

[2] Đảng Cộng sản Việt Nam (2015), "Văn hóa soi đường cho quốc dân đi” (Văn kiện của Đảng về văn hóa), Nxb. Chính trị quốc gia, Hà Nội.

[3] Nguyễn Thị Từ Huy (2013), "Xưng hô trong trường học ngày nay”, http://vietnamnet.vn, truy cập ngày $6 / 01 / 2018$. 
[4] Trần Đình Thích (2011), "Đôi điều suy nghĩ về giáo dục văn hóa giao tiếp trong nhà trường”, Tạp chí Khoa học Trường ĐH Cần Thơ, số 1 .

[5] Đoàn Trọng Thiều (2009), "Giáo dục văn hóa giao tiếp trong nhà trường: giáo dục cái tâm, cái đẹp", Kỷ yếu hội thảo "Giáo dục văn hóa giao tiếp trong nhà trường” tại Trường Đại học Sư phạm TPHCM

[6] Mai Thị Thu (2015), "Văn hóa giao tiếp trong thư viện một số trường đại học trên địa bàn thành phố Hồ Chí Minh”, Tạp chí Khoa học ĐHSP TPHCM, số 10.

[7] Phạm Ngọc Trung (2011), "Văn hóa học đường”, Nxb. Chính trị - Hành chính, Hà Nội.

[8] Nguyễn Quang Uẩn (chủ biên), Nguyễn Văn Lũy - Đinh Văn Vang (2016), "Giáo trình Tâm lí học đại cương”, Nxb. Đại học Sư phạm.

[9] http://www.hui.edu.vn, “Tầm nhìn - Sứ mạng - Mục tiêu chiến lược”, truy cập ngày 2/01/2018.

Ngày nhận bài:10/02/2018

Ngày chấp nhận đăng:27/04/2018 